\title{
RISK OF MORTALITY ASSOCIATED WITH HYPOTHERMIA IN THE NEWBORN BABIES REFERRED TO DR MOEWARDI HOSPITAL
}

\author{
Dwi Hidayah",2), Rina Rohsiswatmo3,4), Yulidar Hafidh1,2) \\ 1)Department of Pediatrics, Division of Neonatology, \\ DR Moewardi Hospital, Surakarta \\ 2)Faculty of Medicine, Universitas Sebelas Maret \\ 3)Department of Pediatrics, Division of Neonatology, \\ DR. Cipto Mangunkusumo Hospital, Jakarta \\ 4)Faculty of Medicine, Universitas Indonesia
}

\begin{abstract}
Background: Hypothermia still a major cause of neonatal morbidity and mortality. World Health Organization (WHO) has set up guidelines in response to the increasing challenges in the management of newborns at risk of hypothermia. This study aimed to investigate the risk of mortality associated with hypothermia in the newborn babies referred to DR Moewardi hospital.

Subjects and Method: A cohort prospective study was conducted at Moewardi hospital, from January $1^{\text {st }}$ to March $31^{\text {st }}, 2015$. A total of 56 neonates was selected for this study. The dependent variable was neonate's mortality. The independent variables were gestational age, birth weight, septicemia, severe respiratory distress, and temperature on admission. The data were collected from medical records. The data were analyzed by multiple logistic regression.

Results: Out of 56 neonates, the incidence of hypothermia was $60.7 \%$ and mortality was $19.6 \%$. Hypothermia $(\mathrm{OR}=11.04 ; 95 \% \mathrm{CI}=1.18$ to $103.27 ; \mathrm{p}=0.001)$ and septicaemia $(\mathrm{OR}=8.03 ; 95 \% \mathrm{CI}=1.65$ to $39.05 ; \mathrm{p}=0.001)$ were statistically associated with neonates mortality. Severe respiratory distress, gestational age, and birth weight were not statistically associated with neonate's mortality.

Conclusion. The incidence of hypothermia on admission is high. Hypothermia and septicemia increase the risk of neonatal mortality.

Keywords: neonate, hypothermia, mortality

\section{Correspondence:}

Dwi Hidayah. Department of Pediatrics, Division of Neonatology, DR Moewardi Hospital, Surakarta/ Faculty of Medicine, Universitas Sebelas Maret. Email: hidayahdwi2@gmail.com. Mobile: +62 8122623728.
\end{abstract}

The $6^{\text {th }}$ International Conference on Public Health Best Western Premier Hotel, Solo, Indonesia, October 23-24, 2019 | 197 https://doi.org/10.26911/the6thicph.03.55 